\title{
PERSPECTIVES
}

\section{Do New Drugs Increase Life Expectancy? A Critique of a Manhattan Institute Paper}

\author{
Dean Baker, $P h D^{7}$ and Adriane Fugh-Berman, $M D^{2,3}$ \\ ${ }^{1}$ Center for Economic and Policy Research, Washington, DC, USA; ${ }^{2}$ Department of Physiology and Biophysics, Georgetown University Medical \\ Center, Washington, DC, USA; ${ }^{3}$ Washington, DC, USA.
}

A recent study published by the Manhattan Institute "Why Has Longevity Increased More in Some States than in Others? The Role of Medical Innovation and Other Factors," purported to show that the more rapid adoption of new drugs has substantial benefits in the form of increased life expectancy, higher productivity and lower non-drug health care expenditures. This study has been cited as evidence supporting the more rapid acceptance of new drugs in Medicaid, Medicare, and other public programs and has helped to shape public debate on the value of new drugs. This analysis questions the key conclusions of the study. It points out that the key statistical regressions appear to be misspecified, since they show anomalies such as a negative correlation between income growth and life expectancy and find no relationship between education and productivity growth. Methodological flaws addressed include lack of adjustment for infant mortality rates; inadequate proxy measures of health status; lack of adjustment for ages of individuals and other sociodemographic factors; inherent problems with the definition of drug age, or 'vintage;' and the failure to consider reverse causation as an obvious explanation for several findings. The Manhattan Institute study does not provide reliable evidence for favoring adoption of newer drugs in either public or private health care programs.

KEY WORDS: longevity; life expectancy; medical innovation; prescription drugs; new drugs; health care costs.

J Gen Intern Med (24)5:678-82

DOI: $10.1007 / \mathrm{s} 11606-009-0954-4$

(c) Society of General Internal Medicine 2009

$\mathrm{D}$ etermining the value of drugs is important for both payers and policymakers. Prescription drugs account for about $10 \%$ of health care spending. ${ }^{1}$ Newer, branded drugs contribute the lion's share of prescription expenses. However, the Pharmaceutical Research and Manufacturers Association claims that new drugs prevent hospitalizations and surgeries and "play a significant role in the life expectancy gains made in the United States and around the world."

Sources of support: none

Received July 26, 2008

Revised January 12, 2009

Accepted March 2, 2009

Published online March 24, 2009
Many citations for claims that improved health offset the higher costs of new drugs can be traced back to studies by Frank Lichtenberg, an economist. Dr. Lichtenberg's work includes at least a dozen studies, mostly released as working papers, that purport to demonstrate the economic benefits of new drugs in the U.S. and other countries. ${ }^{3}$ Although his methodology has been criticized, ${ }^{4-7}$ Lichtenberg's studies have been influential in persuading policymakers that new, expensive drugs are cost-effective. ${ }^{4}$ For example, a Congressional Budget Office Report, Issues in Designing a Prescription Drug Benefit for Medicare, while noting methodological limitations of the studies cited, concludes that, "Nevertheless, the magnitude of the net savings estimated by Lichtenberg suggests that, on balance, patients who took newer drugs were likely to spend less on other kinds of medical care." 8

This paper offers a critique of the theoretical foundation, the model and the external validity of the analysis presented in one Lichtenberg study that purports to show that rapid adoption of new drugs lengthens lives. "Why Has Longevity Increased More in Some States than in Others? The Role of Medical Innovation and Other Factors," published by the Manhattan Institute, compared, by state, increases in life expectancy (at birth and at age 65), productivity, and various measures of health care costs. Adjustments were made for the incidence of AIDS, obesity, smoking, education levels, and income. The analyses include variables intended to pick up effects specific to a particular year (for example, an influenza epidemic) or to a specific state (for example, a newly instituted seat belt law). The rate of adoption of new prescription drugs in each state was calculated using 2004 payment information from state Medicaid programs and Medicare. The study concludes that new drugs enhance life expectancy and growth in productivity (dollar value of output per worker).

Methodological flaws that we will address include lack of adjustment for infant mortality rates; inadequate proxy measures of health status; lack of adjustment for ages of individuals and other sociodemographic factors; inherent problems with Lichtenberg's definition of drug age, or "vintage;" and the failure to consider reverse causation (the assumption that $\mathrm{A}$ causes B when B actually causes A) as an obvious explanation for several findings. Finally, we discuss some of the anomalous results in Lichtenberg's analyses.

\section{LACK OF ADJUSTMENT FOR INFANT MORTALITY}

The Manhattan Institute analysis attributes differences in life expectancy between states to new drugs while failing to control for infant mortality, the single most important determinant of 
life expectancy. Because life expectancy is calculated as an average, death rates in younger age groups have the greatest impact. In the 19th century, when infant deaths were common, life expectancy in 1900 was only 49.24 years. Plunging infant mortality rates (IMRs) increased life expectancy to 68.07 years in 1950 and 75.37 years in $1990 .^{10}$ Between 1990 and 2004, life expectancy increased to 77.9 years. ${ }^{11}$

Disparities in IMRs could account for most differences in longevity in Lichtenberg's analysis (see Fig. 1). Today, the average IMR in the U.S. is 7.1 per 1000 births, but rates range from a low of 4.9 in New Hampshire to a high of 13.5 in the District of Columbia. ${ }^{10}$ Centers for Disease Control data show that IMRs ranged from 5.0-7.2 in the ten states noted by Lichtenberg to have the longest life expectancy. The ten states with the shortest life expectancy had IMRs ranging from 7.1 to 10.4. ${ }^{412}$ Infant mortality affects life expectancy at birth but not at age 65 , which is consistent with the far greater differences reported for life expectancy at birth than at age 65 in the Lichtenberg report.

\section{INADEQUATE PROXY MEASURES OF HEALTH STATUS}

The Manhattan Institute study adjusted for AIDS, obesity, and smoking - an unusual set of variables. Drug therapy has indisputably increased the lifespan of people with AIDS. However, AIDS is not among the 15 leading causes of death in any state in the U.S., so has a dubious role in this type of analysis. Obesity and smoking are risk factors for numerous diseases, but are not acceptable surrogate markers for causes of death.

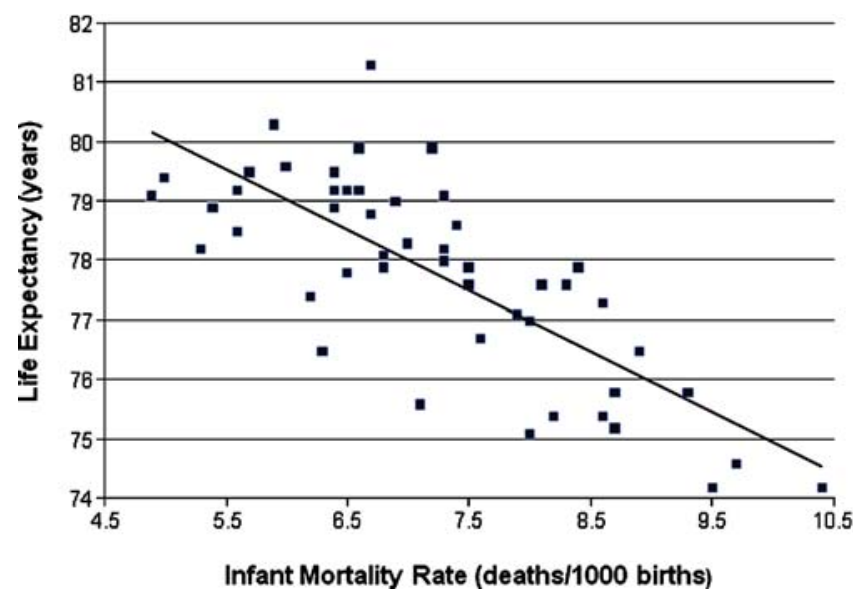

Figure 1. The Relationship Between Infant Mortality Rates and Life Expectancy at Birth in the United States. $r^{2}=0.58$. $P<0.0001$. slope $=$ $-1.02(95 \% \mathrm{Cl}-1.27$ to -0.76$)$. Life expectancy at birth is based on the table "US States ranked by life expectancy" in Lichtenberg, $F$. 2007. Why Has Longevity Increased More in Some States than in Others? The Role of Medical Innovation and Other Factors. ${ }^{9}$ Arizona and Washington, DC were not included in the cited table and are excluded here as well. Data on Infant Mortality Rates were obtained from the National Center for Health Statistics, CDC. Deaths, ageadjusted death rates, and life expectancy at birth, by race and sex; and infant mortality rates, by race: United States, final 2003 and preliminary 2004 . $^{11}$

\section{SOCIODEMOGRAPHIC FACTORS}

Ethnicity, education, income, and other sociodemographic factors are associated with differences in life expectancy. [13] In 2003, there was a gap of 5.3 years between blacks and whites in life expectancy at birth, primarily due to differences in death rates from homicide, heart disease, and HIV. ${ }^{14}$ In 2000, a 25-year-old with a high school degree or less could expect to live another 50 years, while someone who had attended college could expect to live almost another 57 years. ${ }^{15}$ Differences in sociodemographic factors across states could thus contribute to differences in longevity.

\section{DRUG 'VINTAGE'}

The measure of drug age in the Manhattan Institute report is the average year in which the active ingredients in prescription drugs were first approved by the Food and Drug Administration (FDA). This idiosyncratic measure, termed 'drug vintage,' cannot accurately assess the rate of adoption of new drugs because two-thirds of what are considered 'new drugs' are actually different doses, formulations, or combinations of older drugs. Only a third of new drug approvals involve novel drugs, also called "new molecular entities. ${ }^{16}$

Under Lichtenberg's scheme, three 'new' drugs approved by the FDA in 2004 could have three vintages. A novel drug would be 2004 vintage. A new formulation of a drug approved in 1980 would be 1980 vintage. And a new combination of a drug approved in 1980 with a second drug approved in 2000 would be categorized as a 1990 vintage. The fact that two-thirds of new drugs would be classified as older drugs confounds any conclusions about new drugs.

Grouping drugs by age rather than effect is odd; a new acne drug is unlikely to affect lifespan. It would have made more sense to limit this analysis to drugs that affect mortality.

\section{REVERSE CAUSATION}

Reverse causation is not effectively controlled for in the analysis, and could explain several key findings. Rather than new drugs extending lives, older people may use newer drugs. Yet, Lichtenberg's analysis does not control for age. During the years covered by Lichtenberg's analyses (which pre-date Medicare Part D), drugs paid for by Medicare were newer than drugs paid for by Medicaid in every state as revealed in Table 5 of Lichtenberg's paper. ${ }^{9}$ The gap between the mean age of Medicare and Medicaid-covered drugs within some states was as high as eight years - more than twice the difference in age observed across states for Medicare- or Medicaid - covered drugs. This suggests that Medicare recipients, primarily adults over age 65 , used newer drugs more often than younger adults who received drugs only through Medicaid, which covers poor people.

State-to-state variation in the use of specific drugs could also affect the Manhattan Institute's findings. For example, hydrocodone/acetaminophen preparations were two of the ten best-selling drugs between 2002 and 2006. ${ }^{17}$ These are old drugs: acetaminophen was first approved by the FDA in 1951; hydrocodone, an opiate, was first used in cough syrups in the 1930s. Differences in hydrocodone/acetaminophen usage 
Table 1. Estimated Effects of Changes in Drug Vintage* or Population Characteristics

\begin{tabular}{|c|c|c|c|c|c|c|c|c|c|}
\hline & \multicolumn{2}{|c|}{$\begin{array}{l}\text { Change in Life } \\
\text { Expectancy }\end{array}$} & \multirow[t]{2}{*}{ Change in Productivity } & \multicolumn{6}{|c|}{ Change in Expenditures } \\
\hline & $\begin{array}{l}\text { From } \\
\text { Birth }\end{array}$ & $\begin{array}{l}\text { From } \\
\text { Age } 65\end{array}$ & & Drug & $\begin{array}{l}\text { Home } \\
\text { Health Care }\end{array}$ & $\begin{array}{l}\text { Nursing } \\
\text { Home }\end{array}$ & Hospital & Physician & Total \\
\hline 1-y increase Medicaid drug vintage & $0.16 \mathrm{y}$ & $0.09 \mathrm{y}$ & $1.1 \%$ & $3.5 \%$ & $9.0 \%$ & $2.0 \%$ & NS & $-4.0 \%$ & NS \\
\hline 1-y increase Medicare drug vintage & $0.03 \mathrm{y}$ & $0.01 \mathrm{y}$ & NS & $-0.3 \%$ & NS & $0.5 \%$ & $-0.3 \%$ & NS & NS \\
\hline 0.1 unit increase in education index** & NS & NS & NS & $1.6 \%$ & $-2.6 \%$ & $0.6 \%$ & $0.6 \%$ & $1.6 \%$ & $1.1 \%$ \\
\hline $\begin{array}{l}10 \text { percentage point increase in number } \\
\text { of people with health insurance coverage }\end{array}$ & NS & NS & $1.4 \%$ & NS & $21.9 \%$ & $5.7 \%$ & $-2.3 \%$ & $-10.6 \%$ & $-4.2 \%$ \\
\hline $10 \%$ increase in income & $-0.16 \mathrm{y}$ & $-0.09 \mathrm{y}$ & $6.5 \%$ & NS & $7.1 \%$ & $-6.4 \%$ & $4.7 \%$ & $4.8 \%$ & $2.7 \%$ \\
\hline
\end{tabular}

Source: Lichtenberg, F. 2007. Why Has Longevity Increased More in Some States than in Others? The Role of Medical Innovation and Other Factors ${ }^{9}$

The table is based on Table 7, which shows regression results using the fixed-weight Medicaid drug vintage index ${ }^{9}$

* Vintage is defined as the year that the active ingredients in prescription drugs were first approved by the FDA

** In Lichtenberg's analysis, education index is "an index of mean educational attainment of residents of state i in year $t$ "

NS denotes non-significant at the $P<0.05$ level

among states could have a substantial impact on the indices. A $10 \%$ increase in use of hydrocodone/acetaminophen could lower a state's Medicaid vintage by 0.1 year - a very large decline given the limited variation across states.

Opiates are often used in the treatment of cancer and chronic pain. Rather than shortening lives, older drugs may simply be more commonly used by people with life-shortening illnesses - another example of reverse causation.

\section{IMPLAUSIBLE ASSOCIATIONS}

Lichtenberg's analyses linked increased productivity with the use of new drugs, but found no association with education. Increased incomes, however, were associated with shorter lives (see Table 1). Although health insurance coverage was not found to be associated with longevity, coverage was associated with increased productivity and decreased health care expenditures. Contrary to a large body of literature correlating longer lives with higher incomes and socioeconomic status, ${ }^{13,18-21}$ Lichtenberg's regressions also show a strong negative correlation between per capita income and life expectancy both at birth and at age 65 (see Table 1). Lichtenberg concludes that rising income between 1991 and 2004 reduced life expectancy at birth by almost a year ( 0.86 years) and life expectancy at age 65 by six months ( 0.49 years).

Lichtenberg cites several papers to support his finding that higher income lowers life expectancy, but the cited papers actually focused on cyclical changes in income. Within a country, higher income that is associated with more people working or more people working longer hours does lead to transiently higher death rates. ${ }^{22,23}$ However, these studies examined how changes in death rates respond to departures from the normal trend in growth of income, and do not claim to show that life expectancies decline as countries become wealthier

Lichtenberg's analysis may have confused the cyclical, short-term income effects that are highly correlated with specific years with the impact of a long-term trend increase in income. Changes in life expectancy would be more highly correlated with long-term income growth. The impact of rising income was most likely captured by the year variables (coefficients of which were not included.) Including year variables in a regression will likely pick up much of the increase in life expectancy associated with a rising income trend and could lead to the erroneous conclusion that increased income shortens lives.

The conclusion that new drugs enhance growth in productivity (measured as output per worker per year) is based on Medicaid data; Medicare data showed no correlation. The regression that addresses productivity and categories of health care spending indicates that a one-year increase in drug vintage raises productivity by $1.1 \%$ (See Table 1, column 3 ). Extrapolated over the 13-year period of Lichtenberg's analysis, the results imply that newer drugs accounted for a 12.5 percentage point increase in productivity, or nearly half of total productivity growth $(27.0 \%$, based on a $50.3 \%$ increased output $^{24}$ and an $18.3 \%$ increase in the number of employed persons - the denominator in Lichtenberg's productivity term). ${ }^{25}$ This result is implausible.

Other implausible results include Lichtenberg's findings that education was unrelated to productivity, and that health insurance reduces health care expenditures while increasing productivity. The positive association between education and productivity is as strong as an association can be. ${ }^{26}$

Lichtenberg's findings that health insurance coverage had a marginally significant positive relationship with productivity imply that a 10-percentage point increase in health insurance coverage is associated with a $1.4 \%$ rise in productivity. Given current levels of gross domestic product, this would imply that a $10 \%$ increase in coverage would increase output by almost $\$ 200$ billion annually. This result is absurd, because it implies that relatively small increases in health insurance coverage lead to huge jumps in economic output.

The highly significant association between health insurance coverage and reduced health care expenditures (see Table 1) implies that a 10-percentage point increase in health insurance coverage could reduce total health care spending $4.2 \%$. At current levels of health care spending, this implies that expanding health insurance coverage by $10 \%$ would save the country more than $\$ 80$ billion a year. To the contrary, research shows that health care expenses increase with expanded insurance coverage. ${ }^{27-29}$

A peculiar relationship between drug spending and Medicare drug vintages calls into question the ability of these indices to reflect new drug use. While the Medicaid drug vintages show, predictably, that increased use of new drugs is 
associated with higher drug spending, the Medicare results associate increased use of new drugs with reduced drug spending. A review of Lichtenberg's regressions (Table 1) shows that a one-year increase in Medicare drug vintage is associated with a $0.3 \%$ decline in per capita drug spending. Although it seems implausible that more rapid adoption of new drugs would reduce drug expenditures, this anomaly is not addressed in the text.

\section{CONCLUSION}

The report in question purports to support the concept that new drugs save lives. However, the analysis fails to control for differences among states in infant mortality rates, demographics, or causes of death. Inadequate surrogate measures of health status are used, and reverse causation could explain several key findings.

In economic analyses, a statistical regression stands or falls in its entirety. A regression that passes inspection for internal validity should be tested for its ability to withstand manipulation; for example, removing a variable, splitting a time period, or running the regression in two halves should not qualitatively change the results of a robust regression. Lack of internal consistency indicates that there is something wrong.

In the Lichtenberg analysis, the negative relationship between income and life expectancy, the finding that health insurance coverage lowers costs while increasing productivity, and the lack of a relationship between education and productivity are all anomalous results inconsistent with a large body of previous research. The most likely explanation is that the regressions in this analysis were improperly performed.

Previous studies by Lichtenberg have also been criticized. ${ }^{4-6}$ Two previous studies, using Medical Expenditure Panel Survey (MEPS) data, concluded that replacing older drugs with newer drugs would save money. The first study ${ }^{30}$ was criticized for a cross-sectional design inappropriate for determining cause and effect. ${ }^{4}$ Additionally, the use of prescriptions as a unit of analysis rather than people meant that the death of a person using ten drugs would have been counted as ten deaths. ${ }^{5}$ The second study (NBER) failed to control for prior health status and other variables. ${ }^{4}$ An independent reanalysis, using the same data and methodologies in conjunction with more accurate drug approval dates and the consideration of plausible alternative assumptions, could not confirm Lichtenberg's conclusions. ${ }^{4}$ An analysis of cardiovascular drugs that used the same MEPS data set found no association between the use of newer drugs and non-drug expenditures after controlling for the number of drugs or the mix of drugs of different ages. $^{6}$

Lichtenberg's claims that adopting new drugs saves money, increases life expectancy, and increases productivity are unreliable and should not be considered in health policy decisions. Moreover, while some new drugs are therapeutic advances, others are not. For example, the federally-funded ALLHAT study found that chlorthiazide, an older, inexpensive diuretic, was superior to new drugs for treating hypertension. ${ }^{30}$ The CATIE study, also government-funded, found that older antipsychotics are as effective as newer ones for treating schizophrenia. $^{33,34}$

Also, newer drugs may amplify risks rather than benefits. Novel drugs carry more risks than older drugs because problems associated with long-term use or in special populations (for example, the elderly) are revealed only after a drug is in widespread use. ${ }^{35}$ Half of drug withdrawals or black box warnings occur within two years of approval. ${ }^{36}$

The Lichtenberg study argues that there have been very large returns from the development of new drugs in the form of longer life expectancy and in the form of reduced non-drug health care costs and increased productivity. The implication is that the current model of drug development and financing is extremely successful and that altering it, for example through the bulk purchases of drugs in the Medicare prescription drug benefit, could seriously undermine the further development of new drugs.

Our critique shows that Lichtenberg's methods are seriously flawed and his conclusions are therefore unsupportable. In the absence of more compelling research on the impact of newer drugs, policymakers should actively seek ways to contain spending on novel pharmaceuticals. Prescription drugs are the most rapidly growing component of health care costs and will impose a major burden on government budgets and the economy as a whole if they are not reined in.

Acknowledgments: The authors would like to thank Anthony $R$. Scialli MD for helpful comments and creating Figure 1, Alicia M. Bell for formatting and Fran Pollner for editing.

Conflict of Interest: None disclosed.

Corresponding Author: Adriane Fugh-Berman, MD; Department of Physiology and Biophysics, Georgetown University Medical Center, Box 571460, Washington, DC 20057-1460, USA (e-mail: ajf29@georgetown.edu).

\section{REFERENCES}

1. Prescription Drug Trends. Kaiser Family Foundation 2007 (May) Available at http://www.kff.org/rxdrugs/upload/3057_06.pdf. Accessed December 23, 2008.

2. The Value of Medicines: Facts and Figures 2006. Pharmaceutical Research and Manufacturers Association http://www.phrma.org/files/ Value\%20of\%20Medicine\%202006.pdf. Accessed December 24, 2008.

3. EconPapers http://econpapers.repec.org/RAS/pli76.htm. Accessed February 1, 2009.

4. Zhang Y, Soumerai SB. Do newer prescription drugs pay for themselves? A reassessment of the evidence. Health Affairs. 2007;26:880-6.

5. Mintzes B, Lexchin J. Do higher drug costs lead to better health? Can J Clin Pharmacol. 2005;12(1):e22-7.

6. Miller GE, Moeller JF, Stafford RS. New cardiovascular drugs: patterns of use and association with non-drug health expenditures. Inquiry. 2005-2006;42(4):397-412.

7. Lexchin J. The siren call of new drugs. Expert Rev Pharmacoeconomics Outcomes Res. 2003;3(5):513-15

8. Congressional Budget Office. Issues in Designing a Prescription Drug Benefit for Medicare. Available via the Internet at http://cbo.gov/doc. cfm?index $=3960$ or http://cbo.gov/ftpdocs $/ 39 x x /$ doc3960/10-30PrescriptionDrug.pdf. Accessed December 7, 2008.

9. Lichtenberg F. "Why Has Longevity Increased More in Some States than in Others? The Role of Medical Innovation and Other Factors." New York: Manhattan Institute. 2007; Available via the Internet: http://www.man hattan-institute.org/html/mpr_04.htm. Accessed December 24, 2008.

10. National Center for Health Statistics, CDC. U.S. Decennial Life tables for 1989-1991: Trends and Comparisons; 1(3).

11. National Center for Health Statistics, CDC. Deaths, age-adjusted death rates, and life expectancy at birth, by race and sex; and infant mortality rates, by race: United States, final 2003 and preliminary 2004. Available at http://www.cdc.gov/nchs/datawh/statab/unpubd/mortabs.htm. Accessed December 24, 2008. 
12. Centers for Disease Control and Prevention. Racial/Ethnic disparities in infant mortality - United States, 1995-2002. MMWR. 2005;54 (22):553-6

13. Lin CC, Rogot E, Johnson NJ, Sorlie PD, Arias E. A further study of life expectancy by socioeconomic factors in the National Longitudinal Mortality Study. Ethn Dis. 2003;13(2):240-7.

14. Harper S, Lynch J, Burris S, Davey Smith G. Trends in the black-white life expectancy gap in the United States, 1983-2003. JAMA. 2007;297 (11):1224-32

15. Meara ER, Richards S. Cutler DM. The gap gets bigger: changes in mortality and life expectancy, by education, 1981-2000. Health Aff (Millwood). 2008;27(2):350-60.

16. U.S. Food and Drug Administration. "CDER NDAs Approved in Calendar Years 1990-2004 by Therapeutic Potential and Chemical Type," Washington, D.C.: Food and Drug Administration, 2007 [Available via the Internet: http://www.fda.gov/CDER/rdmt/pstable.htm. Accessed December 24, 2008].

17. IMS Health. Top 10 Products by U.S. Dispensed Prescriptions. Available via the Internet: http://www.imshealth.com/deployedfiles/imshealth/ Global/Content/Document/Top-Line\%20Industry\%20Data/2006\%20Top \%2010\%20Products\%20by\%20U.S.\%20Dispensed\%20Prescriptions.pdf. Accessed December 24, 2008.

18. Feinglass J, Lin S, Thompson J, Sudano J, Dunlop D, Song J, Baker DW. Baseline health, socioeconomic status, and 10-year mortality among older middle-aged Americans: findings from the Health and Retirement Study, 1992-2002. J Gerontol B Psychol Sci Soc Sci. 2007;62(4):S209-17.

19. Lin CC, Rogot E, Johnson NJ, Sorlie PD, Arias EA. Further study of life expectancy by socioeconomic factors in the National Longitudinal Mortality Study. Ethn Dis. 2003;13(2):240-7.

20. Muennig P, Franks P, Jia H, Lubetkin E, Gold MR. The incomeassociated burden of disease in the United States. Soc Sci Med. 2005;61 (9):2018-26.

21. Singh GK, Siahpush M. Widening socioeconomic inequalities in US life expectancy, 1980-2000. Int J Epidemiol. 2006;35(4):969-79.

22. Ruhm CJ. Are recessions good for your health? Quarterly Journal of Economics. 2000;115(2):617-50.

23. Ruhm CJ. Good times make you sick. Journal of Health Economics. 2003;22(4):637-58

24. U.S. Department of Commerce, Bureau of Economic Analysis, National Income and Product Accounts, Table 1.1.3, Line 1. Available via the
Internet: http://www.bea.gov/national/nipaweb/SelectTable.asp? Selected $=$ N. Accessed December 24, 2008.

25. U.S. Council of Economic Advisors. Economic Report of the President, 2007, Washington, D.C: U.S. Government Printing Office; 2007, Table B-36.

26. Griliches Z. R\&D, Education, and Productivity: A Retrospective. Cambridge, MA: Harvard University Press; 2000

27. Manning WG, Newhouse JP, Duan N, Keeler EB, Leibowitz A. Health insurance and the demand for medical care: evidence from a randomized experiment. American Economic Review. 1987;77(3):251-77.

28. Cutler DM, Zeckhauser RJ. The anatomy of health insurance. NBER Working Paper No. W7176. National Bureau of Economic Research; 1999

29. Feldman F, Dowd B. A new estimate of the welfare loss of excess health insurance. American Economic Review. 1991;81(1):297-301.

30. Lichtenberg FR. Are the benefits of newer drugs worth their cost? Evidence from the 1996 MEPS.Health Aff (Millwood). 2001;20(5):241-51.

31. Lichtenberg FR. Benefits and Costs of newer drugs: an update. NBER Working Paper no 8996. Cambridge, MA: National Bureau of Economic Research; 2002.

32. Antihypertensive and Lipid-Lowering Treatment to Prevent Heart Attack Trial Collaborative Research Group. Diuretic versus alpha-blocker as first-step antihypertensive therapy: final results from the Antihypertensive and Lipid-Lowering Treatment to Prevent Heart Attack Trial (ALLHAT). Hypertension. 2003;42(3):239-46.

33. Keefe RS, Bilder RM, Davis SM, Harvey PD, Palmer BW, Gold JM Meltzer HY, Green MF, Capuano G, Stroup TS, McEvoy JP, Swart MS, Rosenheck RA, Perkins DO, Davis CE, Hsiao JK, Lieberman JA. CATIE Investigators; Neurocognitive Working Group. Neurocognitive effects of antipsychotic medications in patients with chronic schizophrenia in the CATIE Trial. Arch Gen Psychiatry. 2007;64(6):633-47.

34. Swartz MS, Perkins DO, Stroup TS, Davis SM, Capuano G, Rosen heck RA, Reimherr F, McGee MF, Keefe RS, McEvoy JP, Hsiao JK, Lieberman JA. CATIE Investigators. Effects of antipsychotic medications on psychosocialfunctioning in patients with chronic schizophrenia: findings from the NIMH CATIE study. Am J Psychiatry. 2007;164 (3):428-36.

35. Olson MK. Are novel drugs more risky for patients than less novel drugs? J Health Econ. 2004;23(6):1135-58.

36. Lasser KE, Allen PD, Woolhandler SJ, Himmelstein DU, Wolfe SM, Bor DH. Timing of new black box warnings and withdrawals for prescription medications. JAMA. 2002;287(17):2215-20. 